\title{
Antithrombotic Effects of Different Strains of Lactic Acid Bacteria
}

\author{
Hiromasa Ooe1, Masaru Kato ${ }^{2 *}$, Kanae Hyodo ${ }^{3}$, Keiko Nakashima1, Hiroshi Ashigai1, \\ Kyoko Kato', Toshinori Sasaki ${ }^{4}$, Yuko Fukushima ${ }^{4}$, John C. Giddings ${ }^{5}$, \\ Junichiro Yamamoto ${ }^{3}$ \\ ${ }^{1}$ Research Laboratories for Health Science and Food Technologies, Kirin Company, Limited, Yokohama, Japan \\ ${ }^{2}$ Research Laboratories for Brewing Technologies, Kirin Company, Limited, Yokohama, Japan \\ ${ }^{3}$ Laboratory of Physiology, Faculty of Nutrition, Kobe Gakuin University, Kobe, Japan \\ ${ }^{4}$ Central Laboratories for Key Technologies, Kirin Company, Limited, Yokohama, Japan \\ ${ }^{5}$ Formerly, Department of Haematology, School of Medicine, Cardiff University, UK \\ Email: ${ }^{*}$ kmasaru@kirin.co.jp
}

Received 2 August 2014; revised 17 September 2014; accepted 2 October 2014

Copyright (C) 2014 by authors and Scientific Research Publishing Inc.

This work is licensed under the Creative Commons Attribution International License (CC BY).

http://creativecommons.org/licenses/by/4.0/

(c) (7) Open Access

\begin{abstract}
Objective: The aim of the present study was to assess the antithrombotic properties of different strains of orally available antithrombotic lactic acid bacteria (LAB). Research Methods \& Procedures: Antithrombotic activity, antiplatelet reactivity and/or thrombolytic activity, were measured in seven strains of LAB and LAB cell-free-extracts (LAB filtrates) using the shear-induced platelet reactivity/thrombolytic activity, The Global Thrombosis Test (GTT), with non-anticoagulated rat blood in vitro. Subsequently, the most potent antithrombotic strains identified in vitro were assessed in vivo after oral administration in mouse carotid arteries using a helium-neon laserinduced thrombosis model. Result: Five strains out of seven LAB (Lactobacillus paracasei KW 3100, Lactobacillus fermentum NBRC 3961, Lactobacillus pentosus JCM 8333, Leuconostoc oeni Elios 1, Pediococcus pentosaceus NK-2) promoted significant endogenous thrombolysis in vitro. In addition, one strain (Lactobacillus fermentum NBRC 3961) significantly inhibited shear-induced platelet reactivity. Three antithrombotic strains, Lactobacillus fermentum NBRC 3961, Leuconostoc oeni Elios 1, and Lactobacillus pentosus JCM 8333, were further assessed in vivo. The results demonstrated that filtrates, and the cells per se of these $\mathrm{LAB}$, modulated antiplatelet activity and/or thrombolytic activity, and that the antithrombotic mechanisms were mainly influenced by protein content $(60 \%$ $\mathbf{7 0 \%}$ of dry matter). Conclusion: The findings suggested that some strains of lactic acid bacteria could usefully provide the basis for the production of oral antithrombotic probiotics.
\end{abstract}

\section{Keywords}

Antithrombotic Lactic Acid Bacteria, Shear-Induced Thrombosis, Global Thrombosis Test (GTT),

\footnotetext{
${ }^{*}$ Corresponding author.
}

How to cite this paper: Ooe, H., Kato, M., Hyodo, K., Nakashima, K., Ashigai, H., Kato, K., Sasaki, T., Fukushima, Y., Giddings, J.C. and Yamamoto, J. (2014) Antithrombotic Effects of Different Strains of Lactic Acid Bacteria. Health, 6, 2433-2443. 


\section{Introduction}

Thrombus formation represents an important host defense mechanism in the physiological processes of hemostasis. Thrombus is removed naturally by the thrombolytic system during recovery, but pathologically formed thrombi can occlude blood vessels and cause atherothrombotic diseases such as myocardial infarction and stroke. Unhealthy lifestyles, including excess intake of a high-fat diet and decreased physical activity are known to be significant risk factors for thrombotic diseases [1]. Prevention of atherothrombosis is recognized as a serious social problem in many developed countries.

Many strains of lactic acid bacteria (LAB) have been identified since they were discovered in the $19^{\text {th }}$ century. It is known that LAB are utilized in several fermented products such as liquor, pickle, yoghurt and cheese, and they are widely used as "probiotics". Probiotics are defined as living microorganisms which provide beneficial health effects, such as improvements in gut conditions and allergic diseases, activating immune systems and reducing risk of cancers [2]. In Asia, LAB have been utilized in a number of fermented food products. Epidemiological investigations have shown that the incidence atherothrombotic disease is comparatively less in SouthEast Asia than in other developed countries [3], and it has been postulated that this is partly due to an increased intake of LAB [4] [5].

Recent studies have suggested that LAB indirectly influence thrombogenesis by inhibiting inflammatory reactions. Using a mouse model of pneumococcal pneumonia, Lactobacillus casei was shown to modulate inflammation-coagulation interactions by depressing plasminogen activator inhibitor (PAI-1) [6]. In addition, Bifidobacterium, a health-promoting human intestinal micro biotic, was shown to interact with the plasminogen/plasmin system in vitro [7]. There appears to be little information available, however, on the direct effects of LAB on thrombotic mechanisms.

Previous studies have recognized the importance of pathophysiologically relevant tests to investigate hemostasis in vivo, and techniques such as the helium-neon (He-Ne) laser-induced thrombosis test have been developed for this purpose in animal experiments [8] [9]. In addition, Kovacs et al. devised the technique of Haemostatometry [10] and the Global Thrombosis Test (GTT) [11]-[14] to assess physiological thrombosis in vitro, using non-anticoagulated blood. These methods are governed by shear-induced platelet activation in native blood, and have been shown to reflect the critical balance between thrombotic and thrombolytic activities [15] [16]. The GTT in particular appears to be highly reproducible and suitable for use in humans.

The present study was designed to assess antithrombotic activity, antiplatelet and thrombolytic activities, of different LAB strains using the Global Thrombosis Test (GTT) in vitro and helium-neon (He-Ne) laser-induced thrombosis test in vivo.

\section{Materials and Methods}

\subsection{Animals}

Male Wistar ST rats, aged 13 weeks or older (SLC Co. Ltd, Japan), and male C57BL/6 mice, aged 8 - 10 weeks (SLC Co. Lit), were used. Animals were purchased 1 week before the experiments. Rats and mice were fed a standard solid chow (CE-2, Japan Clea Co. Ltd, Japan) and allowed tap water ad libitum. Animals were maintained in compliance with the "Guiding Principles for the Care and Use of Animals in the field of Physiological Sciences," published by Physiological Society of Japan. The protocol was approved by the Animal Experiment Committee of Kobe Gakuin University and Research Laboratories for Health Science and Food technologies, Kirin Company, Limited. Animals were sacrificed after the test by using Somnopentyl.

\subsection{Bacterial Strains}

Lactobacillus fermentum strain NBRC 3961 was purchased from the National Institute of Technology and Evaluation Biological Resource Center, Japan. Lactobacillus pentosus strain JCM 8333, was obtained from the Japan Collection of Microorganisms, Japan. Pediococcus pentosaceus strain NK-2, was supplied by Biotech Japan Co. Ltd. Each of these strains is known to be found in fermented milk and vegetables. Leuconostoc oeni strain Elios 
1, which is used for adding flavor to wine, was obtained from SCETI Co. Ltd, Japan, and Lactobacillus paracasei strain KW 3110, which we have previously studied for its function in immunity, was available from our own laboratory [17].

\subsection{Preparation of Cells and LAB Filtrates}

The Lactobacillus fermentum strain NBRC 3961, Lactobacillus pentosus strain JCM 8333, and Lactobacillus paracasei strain $\mathrm{KW} 3110$ were cultured at $37^{\circ} \mathrm{C}, 30^{\circ} \mathrm{C}$, and $30^{\circ} \mathrm{C}$, respectively for $24 \mathrm{~h}$ in static MRS broth (Difco, BD Bioscience, USA). Cells were harvested by centrifugation and washed with phosphate buffered saline (PBS, $\mathrm{pH}$ 7.4). The harvested cells were suspended and adjusted to a concentration of $10^{11}$ colony forming units (CFU) with PBS. The cell suspensions were stored at $4^{\circ} \mathrm{C}$ until use. To prepare LAB filtrates, the harvested cells were adjusted to $10^{10} \mathrm{CFU}$ with PBS and then incubated at $37^{\circ} \mathrm{C}$ for $5 \mathrm{~h}$. After incubation, cells were removed by centrifugation and the supernatant was filtered through a filter membrane with a pore size of $0.22 \mu \mathrm{m}$. LAB filtrates were stored at $-80^{\circ} \mathrm{C}$ until use.

\subsection{In Vitro Assessment of Shear-Induced Platelet Reactivity and Endogenous Thrombolytic Activity by the Global Thrombosis Test (GTT)}

The GTT has been described in detail elsewhere [11]-[16]. Figure 1 and Figure 2 show the principles of the test. In summary, when perfectly round ceramic ball bearings are placed in the conical tube (Figure 1), the flat segments prevent the spheres from occluding the lumen. When blood is added to this tube, it flows through the narrow gaps caused by the ball and exits in droplets into an adjacent collecting tube. The latter is trans-illuminated by a light emitter, and a sensor opposite the emitter generates a signal whenever a drop of blood interrupts the light path. In essence, the instrument detects the time interval $(d, \mathrm{~s})$ between consecutive blood drops. At the start, blood flow is rapid and hence $d$ is small. Subsequently, the flow rate gradually decreases and hence $d$ increases. When the $d$ exceeds $15 \mathrm{~s}$ (occlusion- $d$ ), the instrument displays the "Occlusion Time (OT)", which is the time elapsed from the detection of the first drop of blood until detection of occlusion- $d$. Later, the flow is completely arrested. Eventually, due to thrombolysis, the flow is restored as indicated by the detection of blood drop(s). There is also an arbitrarily pre-set value of $d(200 \mathrm{~s})$ for lysis measurement (lysis- $d$ ). When $d$ between the last drop before and the first drop after occlusion exceeds the value of lysis- $d$, the instrument displays the "Lysis Time (LT)", which is calculated as follows: LT = [time of first drop with $d>$ (lysis- $d$ )] - [time of last drop with $d<$ (lysis- $d$ )]. Blood flows at $37^{\circ} \mathrm{C}$ by gravity through the narrow gaps formed between the larger ball bearing and inner wall of the tube, where initial shear rates $\left(15,000-18,000 \mathrm{~s}^{-1}\right)$ activates platelets. These activated platelets remain single, because the very short transit time and high shear stress prevent aggregation. In contrast, in the space distal to the large ball bearing (i.e. the space between the two ball bearings), the shear and turbulent flow favor the formation of large platelet aggregates. Furthermore, in this space between the ball

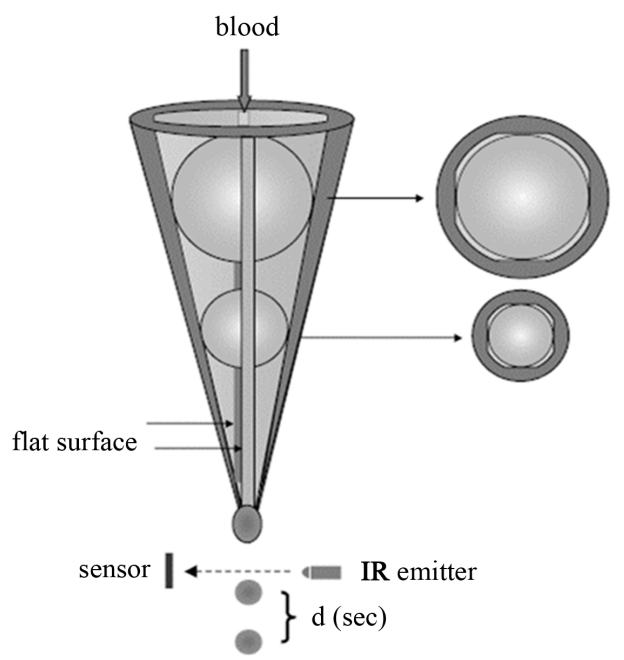

Figure 1. The principles of the global thrombosis test. 


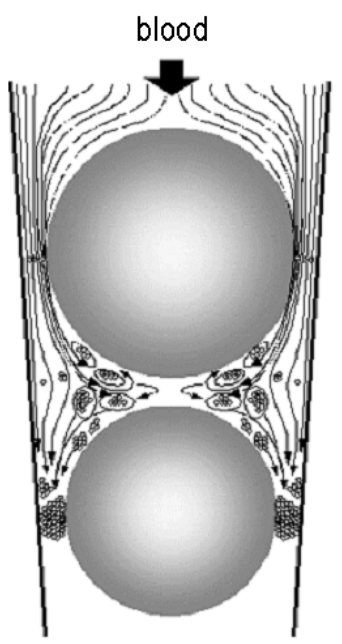

Figure 2. Schematic diagram showing the principle of the global thrombosis test.

bearings, activated platelets generate thrombin and initiate blood coagulation. Flow then carries these fibrinstabilized platelet aggregations into the lower gaps where they are captured, resulting in occlusion of the gaps and arrest of flow. An increase or decrease in OT indicates, respectively, inhibition or enhancement of platelet reactivity. An increase or decrease in LT indicates, respectively, inhibition or enhancement of spontaneous thrombolysis. For the present study, an automated GTT instrument was purchased from Montrose Diagnostics Ltd., UK. For each sample, six parallel measurements were made. The intra-individual variations on OT and LT are $6.07 \%$ and $33.67 \%$, respectively [15].

\subsection{In Vitro Effect of LAB Filtrates on Shear-Induced Platelet Reactivity and Endogenous Thrombolytic Activity}

Thirty minutes after anaesthetization with somnopentyl (60 mg/kg intramuscularly), blood was withdrawn from the abdominal aorta of a rat that had been fasted overnight but allowed water ad libitum. Non-anticoagulated blood was mixed with saline kept at $37^{\circ} \mathrm{C}(1: 1)$, and then $2.7 \mathrm{ml}$ of the diluted blood and $0.3 \mathrm{ml}$ of LAB filtrate or PBS (control) were mixed by inversion in a syringe, and $3.0 \mathrm{ml}$ of the mixture was applied to the GTT tube.

\subsection{In Vivo Assessment of the Antithrombotic Effect}

The laser-induced thrombosis method has been previously described in detail [18]. In brief, mice were anaesthetized with somnopentyl (65 mg/kg intramuscularly). A polyethylene tube (PE-10, Becton Dickinson and Company, USA) was placed in the left femoral artery to inject the dye, and the carotid artery (350 - $450 \mu \mathrm{m}$ in diameter) was exposed by incision. The mouse was placed on a special microscope stage (Olympus Model BH-2, Olympus Co. Ltd, Japan), and then Evans blue dye (30 mg/kg) was injected intra-arterially. Subsequent to the dye, the centre of the exposed carotid artery was irradiated with a laser (Model Neo-50MS, $25 \mathrm{~mW}$ power under the objective lens, Nihon Kagaku Engineering Co. Ltd., Japan). Thrombus formation at the site of irradiation was monitored under epi-illumination and simultaneously recorded on videotape using a CCD camera (Model TMC-7, Takenaka System CO. Ltd, Japan).

\subsection{Oral Administration of LAB Filtrates and Cells in Mice}

LAB filtrates, cell suspensions or PBS (control) were administered by a gastric tube in a volume of $7.7 \mathrm{ml} / \mathrm{kg}$ body weight [18]. They correspond to $8 \times 10^{10}$ and $8 \times 10^{11} \mathrm{CFU} / \mathrm{kg}$ body weight of LAB filtrates and cell suspensions, respectively. The same volume of LAB filtrate, cell suspension or PBS was given again 30 min after the first treatment. The mouse was then anaesthetized and thrombosis experiments started $90 \mathrm{~min}$ after the second oral administration. The antithrombotic or prothrombotic effect was assessed by calculation of the total thrombus size. A smaller size indicated higher antithrombotic activity [19]. 


\subsection{Calculation of Thrombus Size}

Details of this technique have been described elsewhere [20]. An image of the thrombus was computer-analyzed every $10 \mathrm{~s}$. The area of thrombus was outlined, and the mass of thrombus was calculated by multiplication of the area and gray-scale analysis. Image analysis was performed using Image $\mathrm{J}$ software (Image Processing and Analysis Java version 1.30, National Institutes of Health, MD, USA). Thrombotic status was expressed as the total sum of mass measurements in the first 10 min after irradiation.

\subsection{Component Analysis of LAB Filtrates}

1) Dry matter weight

The dry matter weight of LAB filtrates was measured by the freeze drying method. The NET weight was calculated by subtracting the weight of PBS used for extraction.

2) Protein assay

Protein concentration was measured using the DC protein assay kit according to the manufacturer's instructions (Biorad, USA).

3) Saccharides

The saccharide content was measured using the phenol-sulphuric acid method with an analytical curve in glucose [21].

4) Organic acids

Oxalic acid, malic acid, citric acid, succinic acid, pyruvic acid, acetic acid, lactic acid, and phosphoric acid were measured using the Agilent 7100 Capillary Electrophoresis system (Agilent Technologies, USA), with electrophoresis buffer containing 15 mM 2,6-pyridin dicarbonate, 2 mM adenosine 5'-monophosphate, and $0.035 \mathrm{mM}$ hexadimethrine bromide, adjusted to $\mathrm{pH} 5.55$ by $\mathrm{NaOH}$.

\subsection{Mass Spectrometry Analysis and Protein Identification}

Proteins contained in LAB filtrates from Lactbacillus fermentum NBRC 3961 and Lactobacillus pentosus JCM 8333 were separated in a 4\% - 12\% gradient SDS-PAGE gel and stained with colloidal Coomassie. The bold protein bands corresponding approximately to molecular weights of $38 \mathrm{kDa}$ and $47 \mathrm{kDa}$ were excised from the gel. In-gel tryptic digestion of the isolated proteins was carried out as previously described and the digested tryptic peptides were desalted using C-18 Zip-tips [22]. MALDI mass spectrometry was carried out on a Ultraflex II MALDI-TOF/TOF-MS spectrometer (Bruker Daltonics systems, USA). Peptide solution (0.7 $\mu$ l) was mixed with $0.7 \mu \mathrm{l}$ of $10 \mu \mathrm{g} / \mu \mathrm{l}$ HCCA ( $\alpha$-cyano-4-hydroxycinnamic acid) in $90 \%$ aqueous acetonitrile: $0.5 \%$ trifluoroacetic acid. The mixture $(1 \mu \mathrm{l})$ was spotted onto a MALDI target plate and allowed to crystallize. Identification of proteins from MALDI-TOF/TOF-MS spectra was achieved using MS/MS Ion Search of Mascot (Matrix Science, USA) against SWISS-PROT database [23].

\subsection{Statistical Analysis}

GTT measurements were analyzed by repeated ANOVA, followed by post-hoc Dunnett's test. Thrombus size was analyzed by unpaired ANOVA, followed by post-hoc Dunnett's test. Values were expressed as the mean \pm SEM. A value of $P<0.05$ was considered as the limit of significance.

\section{Results}

\subsection{Effect of LAB Filtrates on Shear-Induced Platelet Reactivity and Endogenous Thrombolysis in Vitro}

The effects of LAB filtrates on platelet reactivity and endogenous thrombolysis are shown in Table 1. The undiluted filtrates of Lactobacillus paracasei KW 3110 and Pediococcus pentosaceus NK-2 significantly shortened LT but had no effect on OT, suggesting weak antithrombotic activity in vivo. Lactobacillus pentosus JCM 8333 and Leuconostoc oeni Elios 1 significantly shortened LT but had no effect on OT. These results suggested, however, greater antithrombotic activity in vivo compared with Lactobacillus paracasei KW 3110 and Pediococcus pentosaceus NK-2. Lactobacillus fermentum NBRC 3961 significantly prolonged OT and shortened LT, suggesting strongest antithrombotic activity in vivo amongst the LAB strains tested. On the basis of these 
Table 1. Effect of LAB filtrates on shear-induced platelet reactivity and endogenous thrombolysis in vitro.

\begin{tabular}{|c|c|c|c|}
\hline Variety & Dilution & Occlusion time & Lysis time \\
\hline Lactobacillus paracasei KW 3100 & $\begin{array}{l}\text { Control } \\
\times 100 \\
\times 10 \\
\times 1\end{array}$ & $\begin{array}{l}275.9 \pm 14.5 \\
238.1 \pm 16.7 \\
241.6 \pm 15.5 \\
258.9 \pm 18.7\end{array}$ & $\begin{array}{l}571.6 \pm 18.4 \\
590.4 \pm 31.9 \\
469.3 \pm 48.0 \\
444.8 \pm 16.0^{*}\end{array}$ \\
\hline Lactobacillus fermentum NBRC 3961 & $\begin{array}{l}\text { Control } \\
\times 100 \\
\times 10 \\
\times 1\end{array}$ & $\begin{array}{c}240.6 \pm 6.8 \\
237.2 \pm 7.2 \\
241.3 \pm 8.3 \\
291.0 \pm 16.8^{* * *}\end{array}$ & $\begin{array}{c}597.7 \pm 55.9 \\
593.8 \pm 40.8 \\
550.5 \pm 51.1 \\
476.4 \pm 34.2^{*}\end{array}$ \\
\hline Lactobacillus pentosus JCM 8333 & $\begin{array}{l}\text { Control } \\
\times 100 \\
\times 10 \\
\times 1\end{array}$ & $\begin{array}{l}237.0 \pm 12.7 \\
242.4 \pm 11.4 \\
247.4 \pm 15.1 \\
209.0 \pm 29.7\end{array}$ & $\begin{array}{c}610.7 \pm 29.2 \\
606.5 \pm 23.4 \\
528.4 \pm 25.6 \\
307.8 \pm 27.2^{* *}\end{array}$ \\
\hline Leuconostoc oeni Elios 1 & $\begin{array}{c}\text { Control } \\
\times 100 \\
\times 10 \\
\times 1\end{array}$ & $\begin{array}{c}216.3 \pm 9.8 \\
215.2 \pm 10.9 \\
220.1 \pm 10.7 \\
216.9 \pm 9.8\end{array}$ & $\begin{array}{c}778.3 \pm 45.5 \\
635.2 \pm 44.3^{*} \\
612.4 \pm 41.8^{*} \\
518.8 \pm 30.9^{* *}\end{array}$ \\
\hline Pediococcus pentosaceus NK-2 & $\begin{array}{c}\text { Control } \\
\times 100 \\
\times 10 \\
\times 1\end{array}$ & $\begin{array}{l}239.1 \pm 7.3 \\
227.0 \pm 5.4 \\
226.3 \pm 6.2 \\
224.3 \pm 4.0\end{array}$ & $\begin{array}{c}645.0 \pm 23.5 \\
664.8 \pm 25.1 \\
625.8 \pm 44.4 \\
607.6 \pm 43.6^{*}\end{array}$ \\
\hline
\end{tabular}

Filtrates from the culture media of lactic acid bacteria were mixed with non-anticoagulated rat blood (diluted two-fold with saline), and the effect on shear-induced platelet reactivity and endogenous thrombolytic activity was assessed by GTT in vitro. The results were expressed as the mean \pm SEM. The control was PBS. ${ }^{*} P<0.05 ;{ }^{* * *} P<0.01 . n=6$ in each group.

findings, three strains Lactobacillus fermentum NBRC 3961, Lactobacillus pentosus JCM 8333 and Leuconostoc oeni Elios 1 were selected for further investigation in vivo.

\subsection{In Vivo Thrombotic Status after Oral Administration of LAB Filtrates}

The antithrombotic effects in vivo of these three selected LAB strains were measured the He-Ne laser-induced thrombosis test in mice after oral administration. The results are shown in Figure 3. The filtrate of Lactobacillus fermentum NBRC 3961 showed significantly antithrombotic effects in vivo. The filtrate of Lactobacillus pentosus JCM 8333 also showed significantly antithrombotic effects in vivo. However, the filtrate of Leuconostoc oeni Elios 1 did not show a significant antithrombotic effect in these experiments in vivo.

\subsection{In Vivo Thrombotic Status after Oral Administration of Cell Suspensions}

The results are shown in Figure 4. As the filtrate of Leuconostoc oeni Elios 1 did not show antithrombotic effect in vivo, this strain and others were given at a cell concentration 10 times higher than the original cell concentration of other LAB filtrate. All cell suspensions tested showed antithrombotic effect under these conditions in vivo.

\subsection{Component Analysis of LAB Filtrates}

Analysis of filtrates from Lactobacillus pentosus JCM 8333 and Lactobacillus fermentum NBRC 3961 identified $80 \%$ to $90 \%$ of the ingredients in the whole dry matter weights. Protein was the main ingredient, and comprised $60 \%$ to $70 \%$ of dry matter. Organic acids (lactic acid and acetic acid) were about $5 \%$ to $10 \%$, and saccharides were about 10\% (Figure 5). SDS electrophoresis detected about 20 different proten bands, the most prominent of which were 38 and $47 \mathrm{kDa}$. These peptides were identified as GAPDH and enolase respectively, by MALDITOF/TOF-MS spectrometry analysis (Figure 6). The origin of the enolase in the Lactobacillus pentosus JCM 8333 filtrate was identified L. plantarum, most likely because these two species are genetically close. 


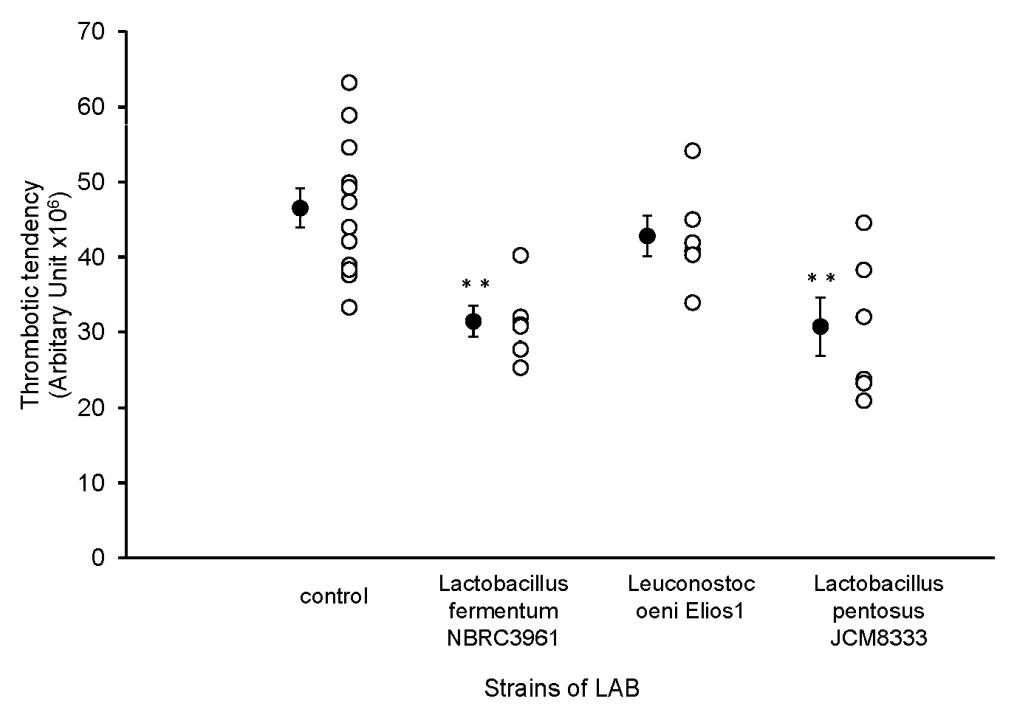

Figure 3. The effect of oral administration of LAB filtrates on thrombotic status in vivo. Results are expressed as the mean \pm SEM. The control was PBS. ${ }^{*} P$ $<0.05 ;{ }^{* *} P<0.01 . n=6$ in each group.

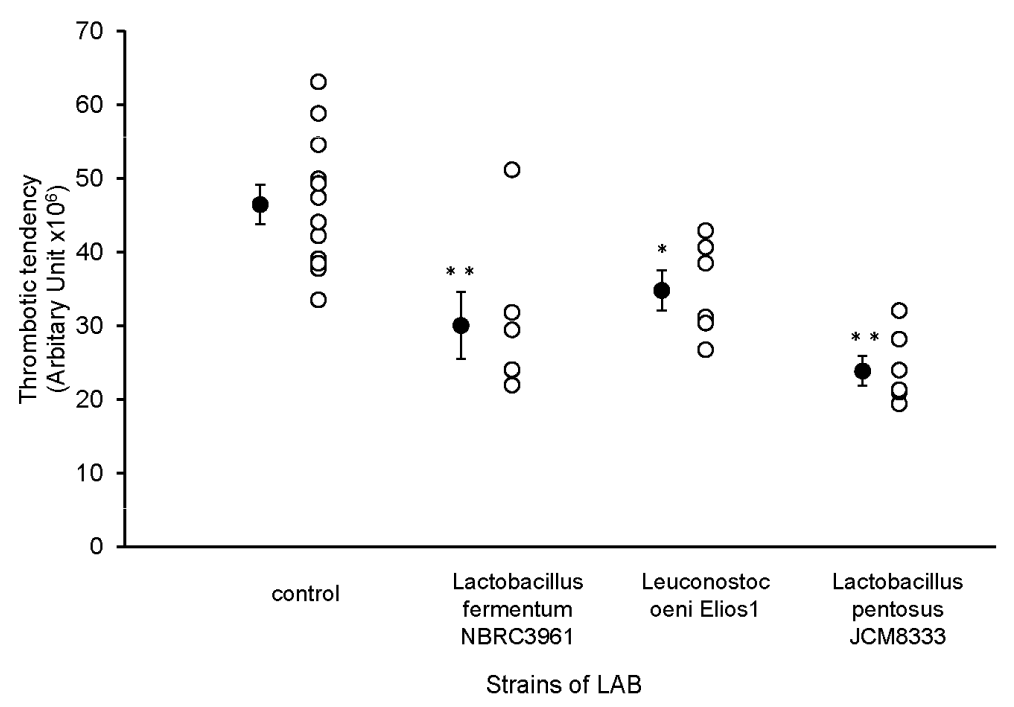

Figure 4. The effect of oral administration of LAB cell suspensions on thrombotic status in vivo. Results are expressed as the mean \pm SEM. The control was PBS. ${ }^{*} P<0.05 ;{ }^{* *} P<0.01 . n=6$ in each group.

\section{Discussion}

Atherothrombotic diseases are a serious medical and social problem in many developed countries. One of the most effective and economical ways to prevent atherothrombotic diseases appears to be daily intake of an antithrombotic diet. Characterising the content of diets of this nature is not straightforward, however. In the present study we employed the GTT method together with a laser-induced thrombosis model in animal experiments to investigate the potential impact of a diet including LAB products on thrombotic mechanisms. The GTT is a point-of-care test, and uses non-anticoagulated blood. Platelets in the native blood are activated by shear force, facilitating the measurement of thrombosis-risk factors by assessing platelet reactivity and thrombolytic responses. This combination tests is known to be pathophysiologically relevant to thrombosis in vivo [15] [16] [18] [20] [24]-[32]. The GTT in particular is believed to provide useful data for investigating physiological mechanisms in humans. 


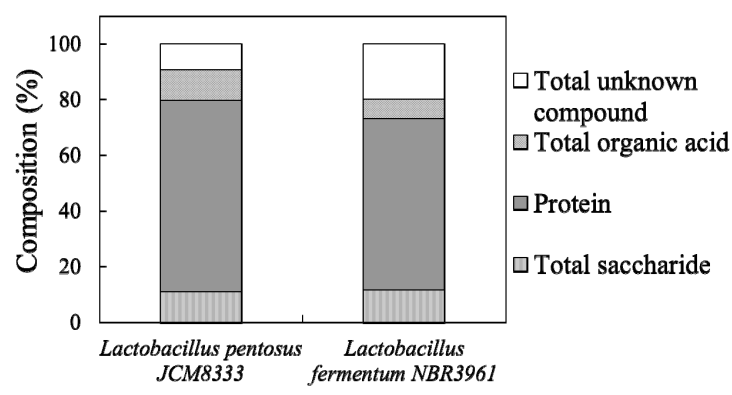

Figure 5. Component analysis of LAB filtrates. The dry matter weights of LAB filtrates were measured by the freeze drying method. Protein concentration was measured using the DC protein assay kit. Saccharide content was measured by the phenol-sulphuric acid method. Organic acids were measured using the Agilent 7100 Capillary Electrophoresis system.

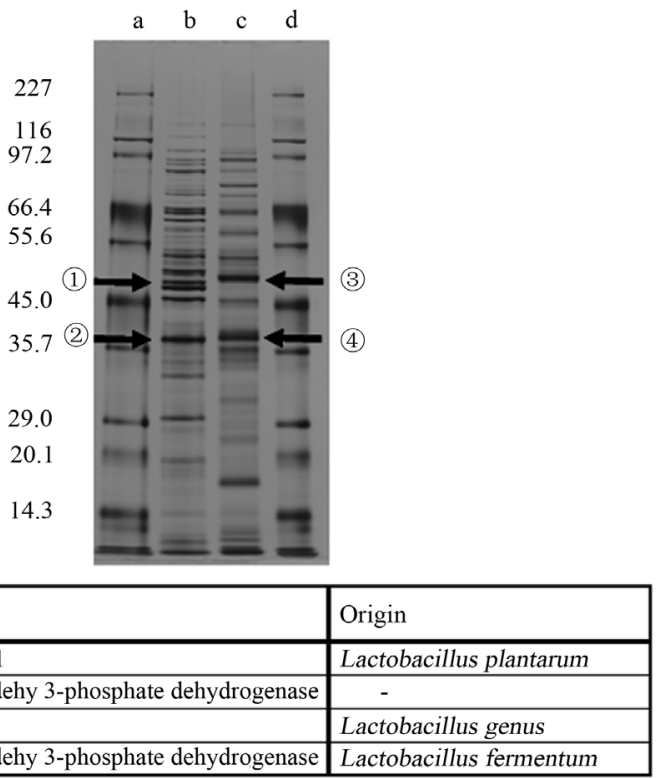

Figure 6. Protein identification of LAB filtrates. LAB filtrates were separated by a $4 \%-12 \%$ gradient gel SDS-PAGE. a, d: molecular weight merker; b: Lactobacillus pentosus JCM 8333; c: Lactobacillus fermentum NBRC 3961. The thickest bands (indicated as arrows), close to 38 and $47 \mathrm{kDa}$, were identified by MALDI-TOF/ TOF-MS spectrometry analysis, respectively.

The present results demonstrated that oral intake of some LAB strains had antithrombotic effects. Initially, filtrates from Lactobacillus fermentum NBRC 396, Lactobacillus pentosus JCM 8333 and Leuconostoc oeni Elios 1 were shown to significantly influence thrombolysis in vitro. The filtrate from Lactobacillus fermentum appeared also to promote antiplatelet activity in vitro. In addition, filtrates from Lactobacillus fermentum NBRC 3961 and Lactobacillus pentosus JCM 8333 were shown to mediate antithrombotic effects in vivo. Subsequently, cell suspensions from all three strains demonstrated antithrombotic activity in the in vivo model. The findings suggested that the effects of these products on hemostasis were governed by antiplatelet activity and/or thrombolytic activity.

The doses of LAB given to the animals in the present study were equivalent to ten commercial yoghurt (100 billion cells/person/day). This might be considered to be difficult to achieve in humans. Nevertheless, it is known that some LAB can survive for long periods in the intestinal tract [33], and even in small quantities, active components of such LAB strains could be continually released into the intestinal tract and have beneficial effects. The antithrombotic potential appeared to be quantitatively different with various LAB strains, but the 
Table 2. Comparison of amino acid sequences of plasminogen binding site (BS1 and BS2) of the enolase from various LABs.

\begin{tabular}{|c|c|c|}
\hline Strain & BS1 & BS2 \\
\hline Lactobacillus fermentum & dvaaselwnded kk y $\mid \mathrm{lhw}$ & $-\mathrm{nr}$ \\
\hline Lactobacillus plantrum & dcaasefyneetgkydlkg & $-\mathrm{sk}$ \\
\hline Leuconostoc oeni & dvasselydadtkk $\mathrm{y} \mid \mathrm{k}] \mathrm{k}$ & -qg \\
\hline Pediococcus pentosaceus & dvaaselwnded|kk|y|k|rw & $-n k$ \\
\hline Lactobacillus paracasei & daaasyfynhdt|knydfeg|k & $-f d$ \\
\hline
\end{tabular}

Lysine residues were boxed.

data indicated LABs have a common antithrombotic effect. All five of the LAB filtrates tested in vitro shortened the lysis time, and all three of the LAB suspensions tested in vivo mediated significant decreases in thrombotic status.

LAB are known to secrete organic acids, such as lactic acid, together with many functional proteins [34]. Our findings indicated that the main active component of Lactobacillus pentosus JCM 8333 and Lactobacillus fermentum NBRC 3961 was contained in the protein fraction. Furthermore, GAPDH and enolase appeared to be the major active peptides. Other studies have demonstrated that GAPDH and enolase on bacterial cell surfaces accelerate host invasion, and activate the plasminogen-plasmin system [35]-[40]. Moreover, direct interactions of GAPDH and enolase with plasminogen have been reported in LAB and Bifidobacteria, which are non-pathogenic organisms [41] [42]. Candela et al. reported that Bifidobacterial enolase on the cell surface has a secondary "moonlighting function" as the receptor for plasminogen in vitro. These workers and others have further emphasised that cell surface enolase might have an important role in the process of interaction with the host by influencing plasmin-related mechanisms [7] [42] [43]. Moreover, enolase binding sites (BS1, BS2) for plasminogen in Lactobacillus plantarum have been identified, and lysine residues appear to be important for the binding properties [42]. The amino acid sequences of enolase from the LAB tested in present study are shown in Table 2. BS1 lysine residues were identified in all LABs, although surrounding amino acid sequences were different. Lysine residues were not detected, however, in the C-terminal BS2 from three of the five LAB strains. Our findings suggested that the differences in antithrombotic potential of these strains might be due to distinct interactions with plasminogen, mediated by specific amino acid sequences in BS1 and BS2. Further studies are warranted to precisely characterize the active components of LAB.

\section{Conclusion}

The antithrombotic properties of orally available lactic acid bacteria (LAB) were assessed using shear-induced platelet reactivity/thrombolytic activity (GTT) in vitro and helium-neon laser-induced thrombosis model in vivo. The results suggested that some strains of LAB could be beneficial to prevent thrombotic disorders.

\section{Acknowledgements}

The authors thank Y. Kawachi and H. Yajima, Research Laboratories for Health Science and Food technologies, Kirin Company, Limited, for comments and discussion.

\section{References}

[1] Lichtenstein, A.H., Appel, L.J., Brands, M., Carnethon, M., Daniels, S., Franch, H.A., Franklin, B., Kris-Etherton, P., Harris, W.S., Howard, B., Karanja, N., Lefevre, M., Rudel, L., Sacks, F., Van Horn, L., Winston, M. and Wylie-Rosett, J. (2006) Summary of American Heart Association Diet and Lifestyle Recommendations Revision 2006. Arteriosclerosis, Thrombosis, and Vascular Biology, 26, 2186-2191. http://dx.doi.org/10.1161/01.ATV.0000238352.25222.5e

[2] Masood, M.I., Qadir, M.I., Shirazi, J.H. and Khan, I.U. (2011) Beneficial Effects of Lactic Acid Bacteria on Human Beings. Critical Reviews in Microbiology, 37, 91-98. http://dx.doi.org/10.3109/1040841X.2010.536522

[3] White, R.H. and Keenan, C.R. (2009) Effects of Race and Ethnicity on the Incidence of Venous Thromboembolism. Thrombosis Research, 123, S11-S17. http://dx.doi.org/10.1016/S0049-3848(09)70136-7

[4] Rhee, S.J., Lee, J.-E. and Lee, C.-H. (2011) Importance of Lactic Acid Bacteria in Asian Fermented Foods. Microbial Cell Factories, 10, S5. http://dx.doi.org/10.1186/1475-2859-10-S1-S5 
[5] Tholstrup, T. (2006) Dairy Products and Cardiovascular Disease. Current Opinion in Lipidology, 17, 1-10.

[6] Haro, C., Villena, J., Zelaya, H., Alvarez, S. and Aguero, G. (2009) Lactobacillus casei Modulates the InflammationCoagulation Interaction in a Pneumococcal Pneumonia Experimental Model. Journal of Inflammation, 6, 28. http://dx.doi.org/10.1186/1476-9255-6-28

[7] Candela, M., Biagi, E., Centanni, M., Turroni, S., Vici, M., Musiani, F., Vitali, B., Bergmann, S., Hammerschmidt, S. and Brigidi, P. (2009) Bifidobacterial Enolase, a Cell Surface Receptor for Human Plasminogen Involved in the Interaction with the Host. Microbiology, 155, 3294-3303. http://dx.doi.org/10.1099/mic.0.028795-0

[8] Kovács, I.B., Tigyi-Sebes, A., Trombitás, K. and Görög, P. (1975) Evans Blue: An Ideal Energy-Absorbing Material to Produce Intravascular Microinjury by HE-NE Gas Laser. Microvascular Research, 10, 107-124. http://dx.doi.org/10.1016/0026-2862(75)90025-4

[9] Yamamoto, J., Iizumi, H., Hirota, R., Shimonaka, K., Nagamatsu, Y., Horie, N. and Morita, S. (1989) Effect of Physical Training on Thrombotic Tendency in Rats: Decrease in Thrombotic Tendency Measured by the He-Ne LaserInduced Thrombus Formation Method. Haemostasis, 19, 260-265.

[10] Ratnatunga, C.P., Edmondson, S.F., Rees, G.M. and Kovacs, I.B. (1992) High-Dose Aspirin Inhibits Shear-Induced Platelet Reaction Involving Thrombin Generation. Circulation, 85, 1077-1082. http://dx.doi.org/10.1161/01.CIR.85.3.1077

[11] Yamamoto, J., Yamashita, T., Ikarugi, H., Taka, T., Hashimoto, M., Ishii, H., Watanabe, S. and Kovacs, I.B. (2003) Görög Thrombosis Test: A Global in Vitro Test of Platelet Function and Thrombolysis. Blood Coagulation \& Fibrinolysis, 14, 31-39. http://dx.doi.org/10.1097/00001721-200301000-00007

[12] Yamamoto, J., Inoue, N., Otsui, K., Ishii, H. and Gorog, D.A. (2014) Global Thrombosis Test (GTT) Detects Major Determinants of Hemostasis Including Platelet Reactivity, Endogenous Fibrinolytic and Thrombin Generating Potential. Thrombosis Research, 133, 919-926. http://dx.doi.org/10.1016/j.thromres.2014.02.018

[13] Saraf, S., Christopoulos, C., Salha, I.B., Stott, D.J. and Gorog, D.A. (2010) Impaired Endogenous Thrombolysis in Acute Coronary Syndrome Patients Predicts Cardiovascular Death and Nonfatal Myocardial Infarction. Journal of the American College of Cardiology, 55, 2107-2115. http://dx.doi.org/10.1016/j.jacc.2010.01.033

[14] Gorog, D.A., Yamamoto, J., Saraf, S., Ishii, H., Ijiri, Y., Ikarugi, H., Wellsted, D.M., Mori, M. and Yamori, Y. (2011) First Direct Comparison of Platelet Reactivity and Thrombolytic Status between Japanese and Western Volunteers: Possible Relationship to the "Japanese Paradox". International Journal of Cardiology, 152, 43-48. http://dx.doi.org/10.1016/j.ijcard.2010.07.002

[15] Yamamoto, J., Naemura, A., Ura, M., Ijiri, Y., Yamashita, T., Kurioka, A. and Koyama, A. (2006) Testing Various Fruits for Anti-Thrombotic Effect: I. Mulberries. Platelets, 17, 555-564. http://dx.doi.org/10.1080/09537100600759295

[16] Yamamoto, J., Naemura, A., Ijiri, Y., Ogawa, K., Suzuki, T., Shimada, Y. and Giddings, J.C. (2008) The Antithrombotic Effects of Carrot Filtrates in Rats and Mice. Blood Coagulation \& Fibrinolysis, 19, 785-792. http://dx.doi.org/10.1097/MBC.0b013e3283177b19

[17] Fujiwara, D., Inoue, S., Wakabayashi, H. and Fujii, T. (2004) The Anti-Allergic Effects of Lactic Acid Bacteria Are Strain Dependent and Mediated by Effects on Both Th1/Th2 Cytokine Expression and Balance. International Archives of Allergy and Immunology, 135, 205-215. http://dx.doi.org/10.1159/000081305

[18] Yamamoto, J., Taka, T., Yamada, K., Ijiri, Y., Murakami, M., Hirata, Y., Naemura, A., Hashimoto, M., Yamashita, T., Oiwa, K., Seki, J., Suganuma, H., Inakuma, T. and Yoshida, T. (2003) Tomatoes Have Natural Anti-Thrombotic Effects. British Journal of Nutrition, 90, 1031-1038. http://dx.doi.org/10.1079/BJN2003994

[19] Shimizu, M., Sawashita, N., Morimatsu, F., Ichikawa, J., Taguchi, Y., Ijiri, Y. and Yamamoto, J. (2009) Antithrombotic Papain-Hydrolyzed Peptides Isolated from Pork Meat. Thrombosis Research, 123, 753-757. http://dx.doi.org/10.1016/j.thromres.2008.07.005

[20] Ijiri, Y., Miura, M., Hashimoto, M., Fukunaga, C., Watanabe, S., Kubota, A., Oiwa, K., Okuda, T. and Yamamoto, J. (2002) A New Model to Evaluate the Diet-Induced Prothrombotic State, Using He-Ne Laser-Induced Thrombogenesis in the Carotid Artery of Apolipoprotein E-Deficient and Low-Density Lipoprotein Receptor-Deficient Mice. Blood Coagulation \& Fibrinolysis, 13, 497-504. http://dx.doi.org/10.1097/00001721-200209000-00004

[21] Hodge, J.E. and Hofreiter, B.T. (1962) Determination of Reducing Sugars and Carbohydrates. In: Whistler, R.L. and Wolfrom, M.L., Eds., Methods in Carbohydrate Chemistry, Vol. 1, Academic Press, New York, 380-394.

[22] Gonnet, F., Lemaître, G., Waksman, G. and Tortajada, J. (2003) MALDI/MS Peptide Mass Fingerprinting for Proteome Analysis: Identification of Hydrophobic Proteins Attached to Eucaryote Keratinocyte Cytoplasmic Membrane Using Different Matrices in Concert. Proteome Science, 1, 2. http://dx.doi.org/10.1186/1477-5956-1-2

[23] Thiede, B., Höhenwarter, W., Alexander Krah, A., Mattow, J., Schmid, M., Schmidt, F. and Jungblut, P.R. (2005) Peptide Mass Fingerprinting. Methods, 35, 237-247. http://dx.doi.org/10.1016/j.ymeth.2004.08.015 
[24] Naemura, A., Mitani, T., Ijiri, Y., Tamura, Y., Yamashita, T. and Yamamoto, J. (2005) Anti-Thrombotic Effect of Strawberries. Blood Coagulation \& Fibrinolysis, 16, 501-509. http://dx.doi.org/10.1097/01.mbc.0000184737.50594.a8

[25] Yamamoto, J., Yamada, K., Naemura, A., Yamashita, T. and Arai, R. (2005) Testing Various Herbs for Antithrombotic Effect. Nutrition, 21, 580-587. http://dx.doi.org/10.1016/j.nut.2004.09.016

[26] Naemura, A., Ijiri, Y., Kodama, M., Honda, Y. and Yamamoto, J. (2007-2008) A Rice Variety (HYJA-Ri4) Enhances Arterial Thrombus Formation in an Animal Thrombosis Model. Pathophysiology of Haemostasis and Thrombosis, 36, 241-244. http://dx.doi.org/10.1159/000252819

[27] Ichiura, D., Naemura, A., Ura, M., Mori, M. and Yamamoto, J. (2009) Anti-Thrombotic Effect of Potato in Animal Experiments. In: Food, Vol. 3, Special Issue 2, Global Science Books, 8-12.

[28] Hyodo, K., Horii, I., Nishino, M., Giddings, J.C. and Yamamoto, J. (2011) The Antithrombotic Effects of Onion Filtrates in Rats and Mice. Health, 3, 319-325. http://dx.doi.org/10.4236/health.2011.36055

[29] Yamamoto, J., Masuda, M., Hyodo, K. and Iwasaki, M. (2012) Experimental Antithrombotic Effect of Potatoes Harvested in the Autumn. Health, 4, 108-112. http://dx.doi.org/10.4236/health.2012.42017

[30] Morishita, M., Naemura, A., Tamura, Y., Yamaya, H., Tsuda, Y., Okada, Y., Okada, K., Matsuo, O. and Yamamoto, J. (2012) Mechanism of the Experimental Antithrombotic Effect of Some Apple Varieties Involves Enhanced Endogenous Thrombolytic Activity. Interventional Medicine \& Applied Science, 4, 115-124.

[31] Yamada, K., Naemura, A., Sawashita, N., Noguchi, Y. and Yamamoto, J. (2004) An Onion Variety Has Natural Antithrombotic Effect as Assessed by Thrombosis/Thrombolysis Models in Rodents. Thrombosis Research, 114, 213-220. http://dx.doi.org/10.1016/j.thromres.2004.06.007

[32] Naemura, A., Ohira, H., Ikeda, M., Koshikawa, K., Ishii, H. and Yamamoto, J. (2006) An Experimentally Antithrombotic Strawberry Variety Is Also Effective in Humans. Pathophysiology of Haemostasis and Thrombosis, 35, 398-404. http://dx.doi.org/10.1159/000097696

[33] Nishida, S., Michinaka, A., Nakashima, K., Iino, H. and Fujii, T. (2008) Evaluation of the Probiotic Potential of Lactobacillus paracasei KW3110 Based on in Vitro Tests and Oral Administration Tests in Healthy Adults. Journal of General and Applied Microbiology, 54, 267-276. http://dx.doi.org/10.2323/jgam.54.267

[34] Boekhorst, J., Wels, M., Kleerebezem, M. and Siezen, R.J. (2006) The Predicted Secretome of Lactobacillus plantarum WCFS1 Sheds Light on Interactions with Its Environment. Microbiology, 152, 3175-3183. http://dx.doi.org/10.1099/mic.0.29217-0

[35] Parkkinen, J. and Korhonen, T.K. (1989) Binding of Plasminogen to Escerichia coli Adhesion Protein. FEBS Letters, 250, 437-440. http://dx.doi.org/10.1016/0014-5793(89)80772-0

[36] Schaumburg, J., Diekmann, O., Hagendorff, P., Bergmann, S., Rohde, M., Hammerschmidt, S., Jansch, L., Wehland, J. and Karst, U. (2004) The Cell Wall Subproteome of Listeria monocytogenes. Proteomics, 4, 2991-3006. http://dx.doi.org/10.1002/pmic.200400928

[37] Lahteenmaki, K., Edelman, S. and Korthonen, T.K. (2005) Bacterial Metastasis: The Host Plasminogen System in Bacterial Invasion. Trends in Microbiology, 13, 79-85. http://dx.doi.org/10.1016/j.tim.2004.12.003

[38] Sijbrandi, R., Den Blaauwen, T., Tame, J.R.H., Oudega, B., Luirink, J. and Otto, B.R. (2005) Characterization of an Iron-Regulated Alpha-Enolase of Bacteroides fragilis. Microbes and Infection, 7, 9-18. http://dx.doi.org/10.1016/j.micinf.2004.09.013

[39] Bergmann, S. and Hammerschmidt, S. (2007) Fibrinolysis and Host Response in Bacterial Infections. Thrombosis and Haemostasis, 98, 512-520.

[40] Hurmalainen, V., Edelman, S., Antikainen, J., Baumann, M., Lahteenmaki, K. and Korhonen, T.K. (2007) Extracellular Proteins of Lactobacillus crispatus Enhance Activation of Human Plasminogen. Microbiology, 153, 1112-1122. http://dx.doi.org/10.1099/mic.0.2006/000901-0

[41] Candela, M., Miccoli, G., Bergmann, S., Turroni, S., Vitali, B., Hammerschmidt, S. and Brigidi, P. (2008) Plasminogen-Dependent Proteolytic Activity in Bifidobacterium lactis. Microbiology, 154, 2457-2462. http://dx.doi.org/10.1099/mic.0.2008/017095-0

[42] Vastano, V., Capri, U., Candela, M., Sicilliano, R.A., Russo, L., Renda, M. and Sacco, M. (2013) Identification of Binding Sites of Lactobacillus plantarum Enolase Involved in the Interaction with Human Plasminogen. Microbiological Research, 168, 65-72. http://dx.doi.org/10.1016/j.micres.2012.10.001

[43] Jeffery, C.J. (1999) Moonlighting Proteins. Trends in Biochemical Sciences, 24, 8-11. http://dx.doi.org/10.1016/S0968-0004(98)01335-8 
Scientific Research Publishing (SCIRP) is one of the largest Open Access journal publishers. It is currently publishing more than 200 open access, online, peer-reviewed journals covering a wide range of academic disciplines. SCIRP serves the worldwide academic communities and contributes to the progress and application of science with its publication.

Other selected journals from SCIRP are listed as below. Submit your manuscript to us via either submit@scirp.org or Online Submission Portal.
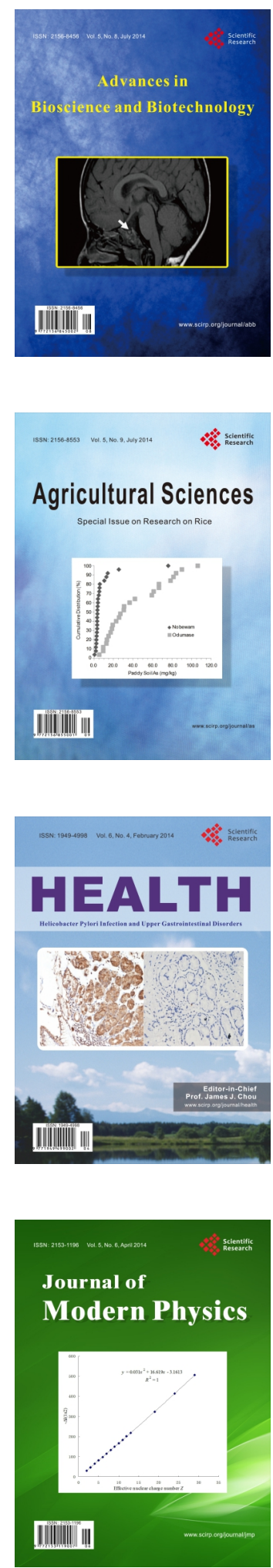
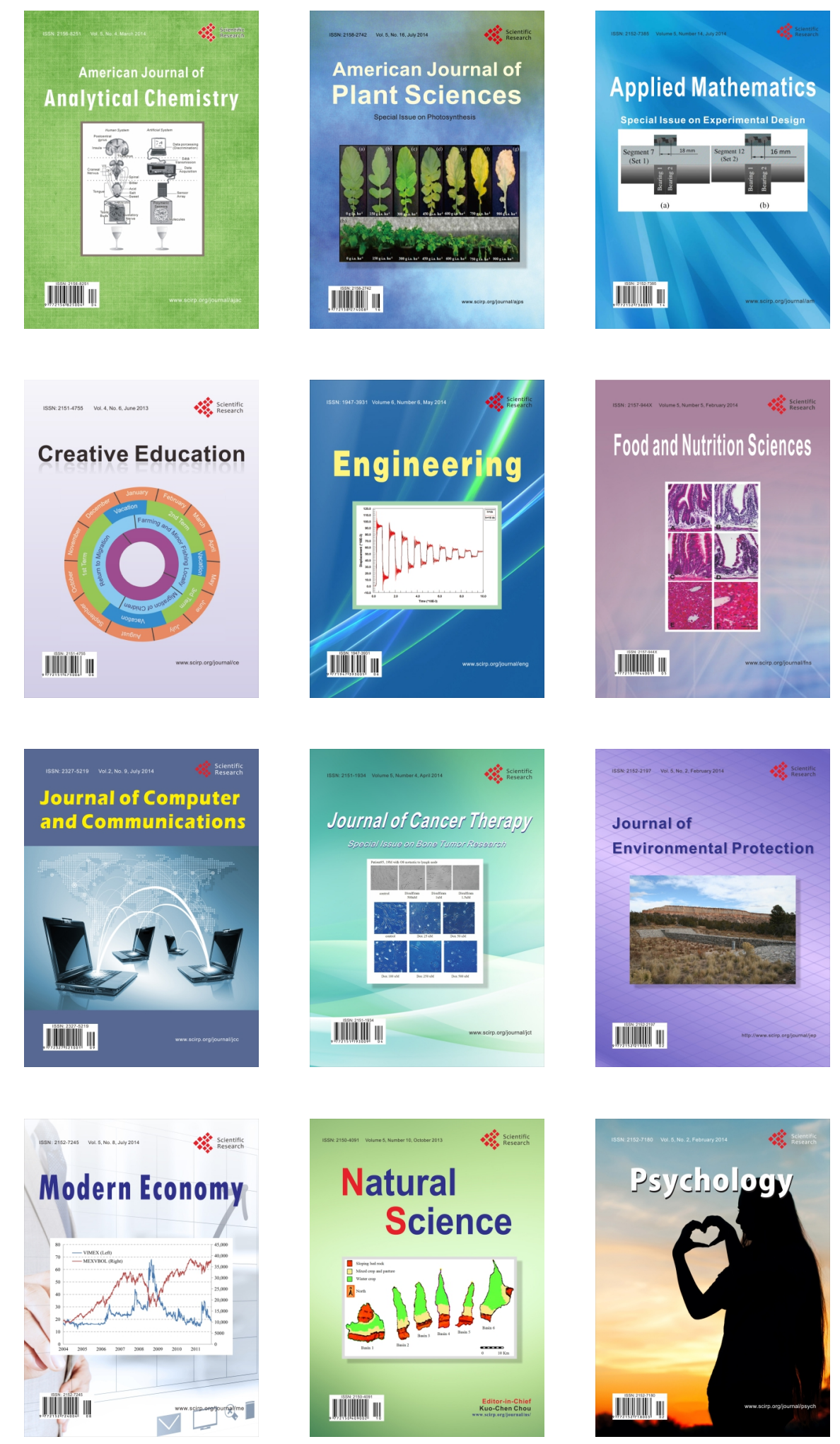